\title{
Morphology of the terminal abdominal segments in females of Triatominae (Insecta: Hemiptera: Reduviidae)
}

\author{
Juliana Mourão dos Santos Rodrigues ${ }^{\mathrm{a}, \mathrm{b}, *}$, João Aristeu da Rosa ${ }^{\mathrm{c}}$, \\ Felipe Ferraz Figueiredo Moreira ${ }^{\mathrm{b}}$, Cleber Galvão $^{\mathrm{a}}$ \\ ${ }^{a}$ Laboratório Nacional e Internacional de Referência em Taxonomia de Triatomíneos, Instituto Oswaldo Cruz, Fundação Oswaldo Cruz, Rio de Janeiro, RJ, Brazil \\ ${ }^{\mathrm{b}}$ Laboratório de Biodiversidade Entomológica, Instituto Oswaldo Cruz, Fundação Oswaldo Cruz, Rio de Janeiro, RJ, Brazil \\ ${ }^{\mathrm{c}}$ Laboratório de Parasitologia, Departamento de Ciências Biológicas, Faculdade de Ciências Farmacêuticas, Universidade Estadual Paulista, Araraquara, SP, Brazil
}

\section{A R T I C L E IN F O}

\section{Keywords:}

Chagas disease

External morphology

Kissing bugs

Taxonomy

\begin{abstract}
A B S T R A C T
Triatominae (Insecta: Hemiptera: Reduviidae) includes 151 extant species that are all potential vectors of Chagas disease. The relationships among these species have been recently studied based on molecular and cytogenetical approaches, and although the morphology of these insects is fairly described, wide comparative studies and cladistics analysis based on this feature are lacking. A comparative study of the terminal abdominal segments in females of 26 species of Triatominae was performed in order to evaluate their importance for the distinction of genera and species, and obtain characters to be used in cladistics analyses. The results showed that the short combined segments IX and X in dorsal view is not diagnostic for Rhodnius, and the elongated trapezoidal dorsal shape of combined segments IX and $\mathrm{X}$ is not exclusive of Panstrongylus. There are diagnostic features at the generic level for Rhodnius and Dipetalogaster, but not for the other genera studied. Among the structures examined, tergite IX is the most valuable for distinguishing species of Triatominae. The female terminalia is useful for the specific identification of Triatominae, but cannot be used to diagnose most genera or to directly assess supraspecific relationships. These can only be unveiled by using additional morphological and/or molecular data in broad cladistics analyses.
\end{abstract}

\section{Introduction}

Kissing bugs (Insecta: Hemiptera: Reduviidae: Triatominae) are widely distributed in the Neotropical Region and represent 151 extant species classified in 18 genera and five tribes (Galvão and de Paula, 2014; Mendonça et al., 2016; Rosa et al., 2017). They are strictly hematophagous during all postembryonic life cycle and vectors of Trypanosoma cruzi (Chagas, 1909), the etiological agent of Chagas disease. Between six and seven million people are infected by this parasite, most from Latin America, and more than ten thousand people die each year due to clinical manifestations of the disease (WHO 2017a,b).

The genera Panstrongylus Berg, Triatoma Laporte and Rhodnius Stål are the most diverse of the subfamily and the most significant epidemiologically, due to their synanthropic habits and domiciliation capacity (Schofield 1994). The first two are included in Triatomini and the last in Rhodniini, which are tribes supported by morphometric and molecular analyses (De Paula et al., 2005; Patterson 2007), with wide morphological and physiological disparities (Schofield and Galvão
2009).

Characteristics commonly used to distinguish genera and species of Triatominae include the general color of the body and legs, and morphological aspects of the head, scutellum and male genitalia (Lent and Wygodzinsky 1979). The female genitalia was described for most species of the subfamily (Lent 1948; Abalos and Wygodzinsky 1951; Sherlock and Serafim 1967; Lent and Jurberg 1968, 1969, 1975), but was considered uniform by previous authors and, therefore, not appropriate for specific identification (Lent and Wygodzinsky 1979).

Rosa et al. (2010) were the first to analyze the terminal abdominal segments in females of Triatominae using scanning electron microscopy, and showed that they in fact have diagnostic value. Subsequently, Rosa et al. (2014) studied the genus Rhodnius in detail, demonstrating that even species very similar in general morphology can be distinguished based on this feature. Having proven useful, this technique was used in the descriptions of $R$. montenegrensis Rosa et al. (2012), $R$. marabaensis Souza et al. (2016) and R. taquarussuensis Rosa et al. (2017). Recently, Rivas et al. (2017) compared this feature in six

\footnotetext{
* Corresponding author at: Laboratório Nacional e Internacional de Referência em Taxonomia de Triatomíneos (LNIRTT), Pavilhão Rocha Lima - $5^{\circ}$ andar, FIOCRUZ, Av. Brasil 4365, Rio de Janeiro, RJ, CEP: 21040-360, Brazil.

E-mail address: julianamourao@yahoo.com.br (J.M.d.S. Rodrigues).
} 
Table 1

Species, collection (CTIOC) or colony number, and origin of the triatomines used in this study.

\begin{tabular}{|c|c|c|}
\hline Species & Collection/colony number & Origin \\
\hline Panstrongylus chinai (Del Ponte, 1929) & CTIOC 1409 & Ecuador, Loja, 2200m \\
\hline P. diasi (Pinto \& Lent, 1946) & CTIOC 1426 & Brazil, Espírito Santo \\
\hline \multirow[t]{2}{*}{ P. geniculatus (Latreille, 1811) } & СTIOC 1295 & Brazil, Espírito Santo, Alegre \\
\hline & CTIOC 1333 & Brazil, Rio de Janeiro, Angra dos Reis, Mambucaba \\
\hline P. guentheri Berg, 1879 & СTIOC 1812 & No locality data \\
\hline \multirow[t]{2}{*}{ P. humeralis (Usinger, 1939) } & CTIOC 1826 & Argentina, Córdoba \\
\hline & CTIOC 1835 & Argentina, Córdoba \\
\hline \multirow[t]{2}{*}{ P. lignarius (Walker, 1873) } & CTIOC 6570 & Peru, Lima, Jesus Maria \\
\hline & “2984” & No locality data \\
\hline P. lutzi (Neiva \& Pinto, 1923) & CTIOC 1424 & Brazil, Ceará, Itatira, Lagoa do Mato \\
\hline \multirow[t]{2}{*}{ P. megistus (Burmeister, 1835) } & CTIOC 1610 & Brazil, Pernambuco, Recife, Nazaré \\
\hline & Colony 119 & Brazil, Minas Gerais, Piranguinho, Esmeril \\
\hline P. rufotuberculatus (Champion, 1899) & CTIOC 1422 & Bolivia \\
\hline P. tupynambaiLent, 1942 & СTIOC 1755 & Brazil, Rio Grande do Sul, Cachoeira do Sul \\
\hline Dipetalogaster maxima (Uhler, 1894) & СТIOC 2715 & Mexico, Baja California Sur \\
\hline Eratyrus mucronatus Stål, 1859 & CTIOC 6538 & No locality data \\
\hline \multirow[t]{2}{*}{ Meccus phyllosomus (Burmeister, 1835) } & No collection number & Mexico \\
\hline & No collection number & Mexico \\
\hline Nesotriatoma bruneri Usinger, 1944 & Colony 129 & Cuba \\
\hline Triatoma barberi Usinger, 1939 & CTIOC 4813 & Mexico, Puebla \\
\hline T. brasiliensis Neiva, 1911 & Colony 04 & Brazil, Ceará, Sobral, Boa Vista \\
\hline T. dimidiata (Latreille, 1811) & Colony 147 & Central America \\
\hline T. infestans (Klug, 1834) & Colony 26 & Argentina, Santa Fé, Santa Fé \\
\hline T. lecticularia (Stål, 1859) & Colony 32 & U.S.A., Oklahoma, Waurika \\
\hline T. maculata (Erichson, 1848) & CTIOC 4581 & Venezuela, Mérida \\
\hline T. matogrossensis Leite \& Barbosa, 1953 & Colony 38 & Brazil \\
\hline T. rubrofasciata (De Geer, 1773) & Colony 145 & Brazil, Pará, Belém \\
\hline T. rubrovaria (Blanchard, 1843) & Colony 143 & Brazil, Rio Grande do Sul, Caçapava do Sul, Serra da Picada \\
\hline T. sordida (Stål, 1859) & Colony 59 & Argentina, Corrientes, San Miguel, zona rural \\
\hline T. tibiamaculata Pinto, 1926 & Colony 68 & Brazil, Santa Catarina, Navegantes \\
\hline Rhodnius brethesi Matta, 1919 & Colony 78 & Brazil, Amazonas, Rio Acará, afluente do rio Negro \\
\hline
\end{tabular}

species of the genus Meccus Stål.

The objective of the present study is to further test the value of the terminal abdominal segments of females in the distinction of genera and species of Triatominae through a comparative analysis of images generated by scanning electron microscopy, and to identify characters to be used in cladistics analyses.

\section{Material and methods}

We studied 26 species of Triatominae included in the genera Panstrongylus (10 species), Dipetalogaster Usinger (1), Eratyrus Stål (1), Meccus Stål (1), Nesotriatoma Usinger (1), Triatoma (11) and Rhodnius (1) (Table 1). Specimens examined were obtained from the Triatomines Collection of the Oswaldo Cruz Institute (CTIOC) and from the colonies kept by the National and International Reference Laboratory in Taxonomy of Triatomines (LNIRTT), Oswaldo Cruz Institute (IOC), Rio de Janeiro, Brazil. One or two females of each species were metalized (Table 1 ) and the search for intraspecific variation included 10 additional specimens of each deposited in the CTIOC, except for P. tupynambai (5).

Specimens from the colonies were killed by freezing and washed with detergent, whereas those from CTIOC were softened in a relaxing chamber and equally washed. Then, transversal cuts were made between abdominal tergites II and III. The dissected abdomens were dehydrated in alcoholic series, placed in a drying oven at $50^{\circ} \mathrm{C}$, and attached to aluminum stubs by their proximal portion.

Subsequently, the structures were metallized in the "Rudolf Barth" Scanning Electron Microscopy Platform (IOC) or in the Chemistry Institute of the São Paulo State University (UNESP, Araraquara, Brazil). Micrographies were obtained in the same institutions by using the microscopes JEOL JSM-6390LV (IOC) and Topcon SM-300 (UNESP). The most evident cases of intraspecific variation were photographed with a digital camera attached to a Leica M205C stereomicroscope and processed using automontage software (LNIRTT).

\section{Results}

\subsection{Dorsal view (Figs. 1-26, Figs.79 and 82; Table 2)}

Tergite VII clearly separated from VIII, except for the median portion in Dipetalogaster maxima (Uhler, 1894) (Fig. 11), in which the division is only clear under higher magnifications. Posterior margin of tergite VII usually straight (Figs. 1-7, 12-13, 16, 18, 20, 23-24), with the following variation: slightly concave ( $P$. tupynambai Lent, 1942, Nesotriatoma bruneri Usinger, 1944, Triatoma barberi Usinger, 1939, T. lecticularia (Stål, 1859), T. maculata (Erichson, 1848), T. rubrofasciata (De Geer, 1773) and T. tibiamaculata Pinto, 1926; Figs. 10, 14-15, 19, 21-22, 25), straight to slightly concave (Panstrongylus megistus (Burmeister, 1835) and P. rufotuberculatus (Champion, 1899); Fig. 8, 9), and straight to slightly sinuous (T. dimidiata (Latreille, 1811) and Rhodnius brethesi Matta, 1919; Figs. 17, 26). Apex of connexivum reaching or surpassing posterior margin of tergite VIII, except in $D$. maxima, where it is much shorter (compare Figs. 10 and 11).

Tergite VIII always clearly separated from IX. Tergite VIII of $R$. brethesi (Fig. 26) much larger than in other species. Posterior margin of tergite VIII usually straight (Figs. 1-7, 10, 13, 15-19, 24-26, 79, 82), except for $P$. megistus, $P$. rufotuberculatus, T. maculata, T. matogrossensis Leite \& Barbosa, 1953, T. rubrofasciata, T. rubrovaria (Blanchard, 1843), T. sordida (Stål, 1859) (slightly convex; Figs. 8-9, 20-23), Eratyrus mucronatus Stål, 1859, N. bruneri (straight to slightly convex; Figs. 12, 14) and D. maxima (convex and swollen; Fig. 11).

Combined abdominal segments IX and $\mathrm{X}$ usually trapezoidal (Figs. 1-2, 4-7, 9-11, 13-17, 19, 21, 79). Differently shaped in $P$. megistus, Eratyrus mucronatus, T. dimidiata, T. rubrofasciata and T. tibiamaculata (elongated trapezoidal; Figs. 8, 12, 17, 22, 25); T. maculata and T. sordida (semi-oval; Figs. 20, 24); T. infestans (Klug, 1834) and T. rubrovaria (semi-oval with expanded posterolateral angles; Figs. 18, 23); and $R$. brethesi (short, much wider than long; Fig. 26). Usually trapezoidal, in P. geniculatus (Latreille, 1811) (Fig. 82), but semi-oval in 


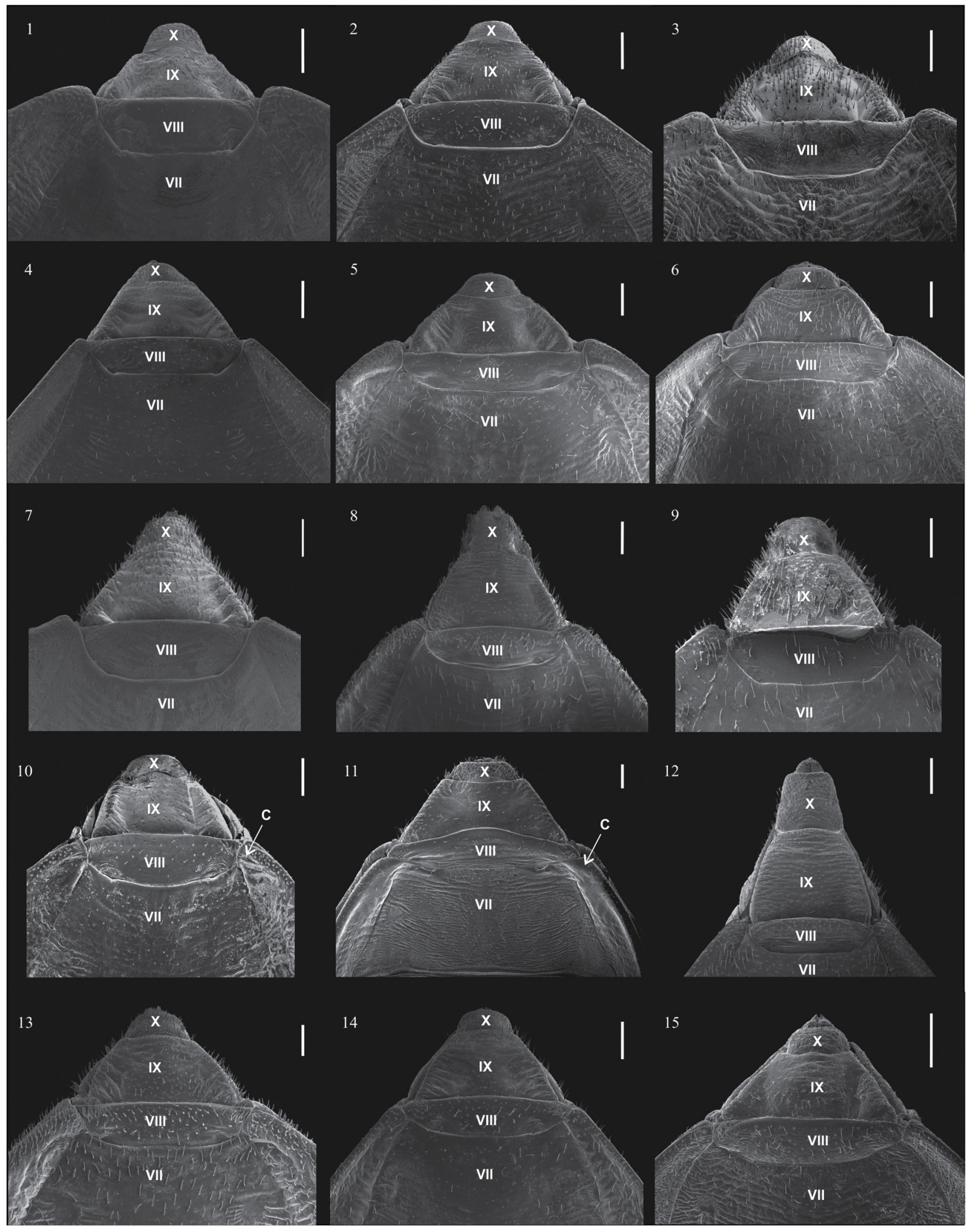

Figs. 1-15. Female external genitalia examined by scanning electron microscopy, dorsal view: 1, Panstrongylus chinai. 2, P. diasi. 3, $P$. geniculatus. 4, $P$. guentheri. 5, $P$. humeralis. 6, P. lignarius. 7, P. lutzi. 8, P. megistus. 9, P. rufotuberculatus. 10, P. tupynambai. 11, Dipetalogaster maxima. 12, Eratyrus mucronatus. 13, Meccus phyllosomus. 14, Nesotriatoma bruneri. 15, Triatoma barberi. (VII and VIII, tergites; IX and X, segments). Scale bars $=500 \mu \mathrm{m}$. 


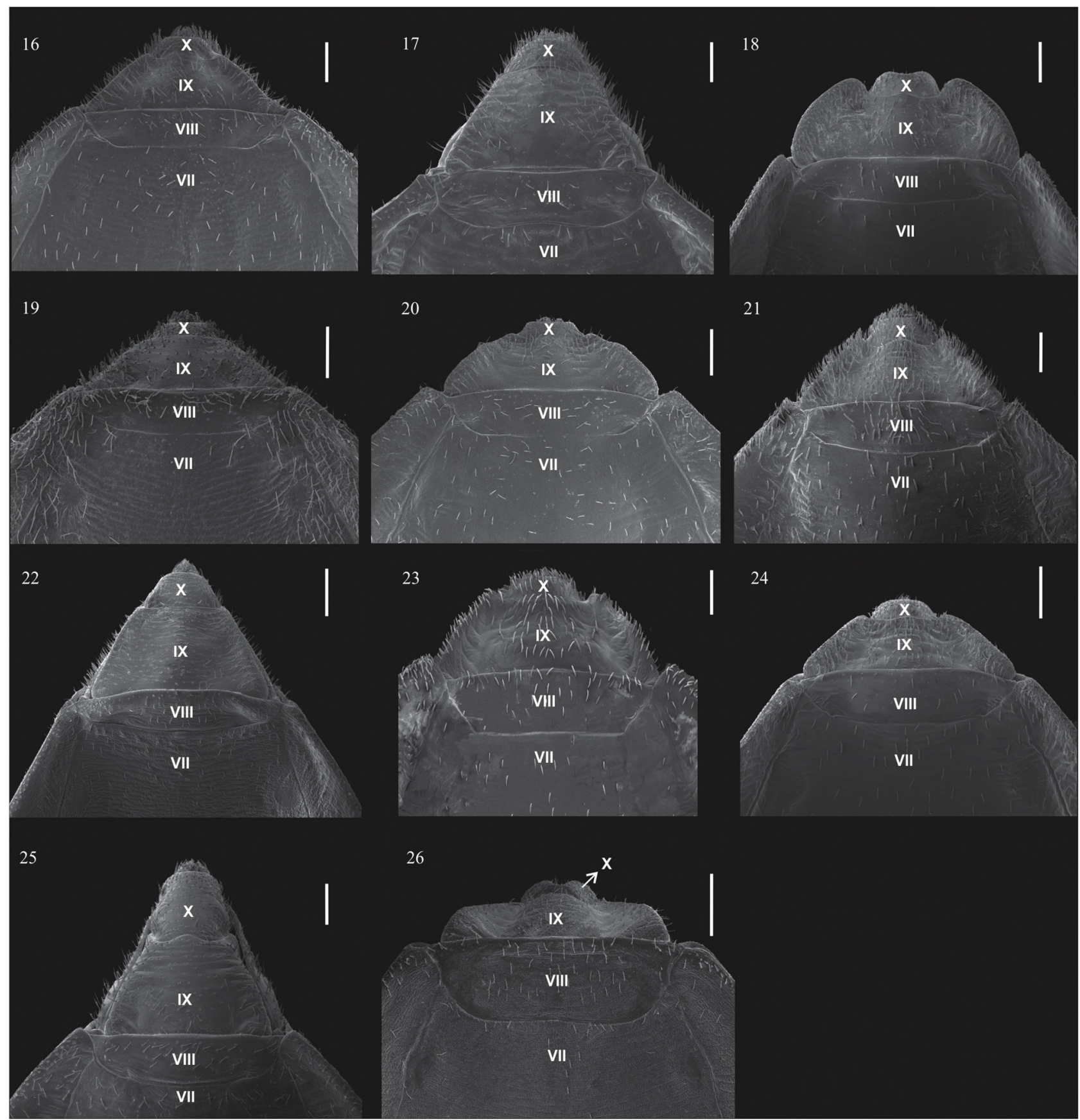

Figs. 16-26. Female external genitalia examined by scanning electron microscopy, dorsal view: 16, Triatoma brasiliensis. 17, T. dimidiata. 18, T. infestans. 19, T. lecticularia. 20, T. maculata. 21, T. matogrossensis. 22, T. rubrofasciata. 23, T. rubrovaria. 24, T. sordida. 25, T. tibiamaculata. 26, Rhodnius brethesi. (VII and VIII, tergites; IX and $\mathrm{X}$ segments). Scale bars $=500 \mu \mathrm{m}$.

some specimens (Fig. 3).

Tergite IX clearly separated from X (Figs. 2-15, 17-26), except for $P$. chinai (Del Ponte, 1929) and T. brasiliensis Neiva, 1911 with tenuous median portion of division (Figs. 1, 16, 79). Panstrongylus lignarius (Walker, 1873) with anterolateral angles more projected than in other species (Fig. 6). Lateral margins of tergite IX straight (Figs. 1-12, 14-17, 19, 21-22, 25-26, 79, 82), straight to slightly convex (Meccus phyllosomus (Burmeister, 1835); Fig. 13); or weakly to strongly expanded (T. infestans, T. maculata, T. rubrovaria, T. sordida; Figs. 18, 20, 23-24). Posterior margin of tergite IX usually straight to slightly convex or slightly concave (Figs. 1-14, 17, 19, 22, 79, 82); weakly to strongly sinuous, forming three lobes, with lateral angles more or less prominent and elevated (Figs. 10, 15-16, 18, 20-21, 23-25); or straight with median region elevated and rounded (R. brethesi; Fig. 26).

Posterior margin of tergite $\mathrm{X}$ not narrowed, straight to curved (Figs. 1-17, 19-25, 79, 82); T. infestans and $R$. brethesi with median notch (Figs. 18, 26). Posterior margin straight to curved in most $P$. geniculatus, but semi-oval in some specimens (Fig. 3).

\subsection{Ventral view (Figs. 27-52, 80, 83; Table 3)}

Posterior margin of sternite VII variably sinuous (Figs. 27-30, $32-40,42,44-47,49-52)$ or straight and centrally projected (P. humeralis (Usinger, 1939), P. megistus, T. barberi, T. dimidiata and T. rubrofasciata; Figs. 31, 34, 41, 43, 48).

Combined abdominal segments VIII-X wider than long (Figs. 27-33, 


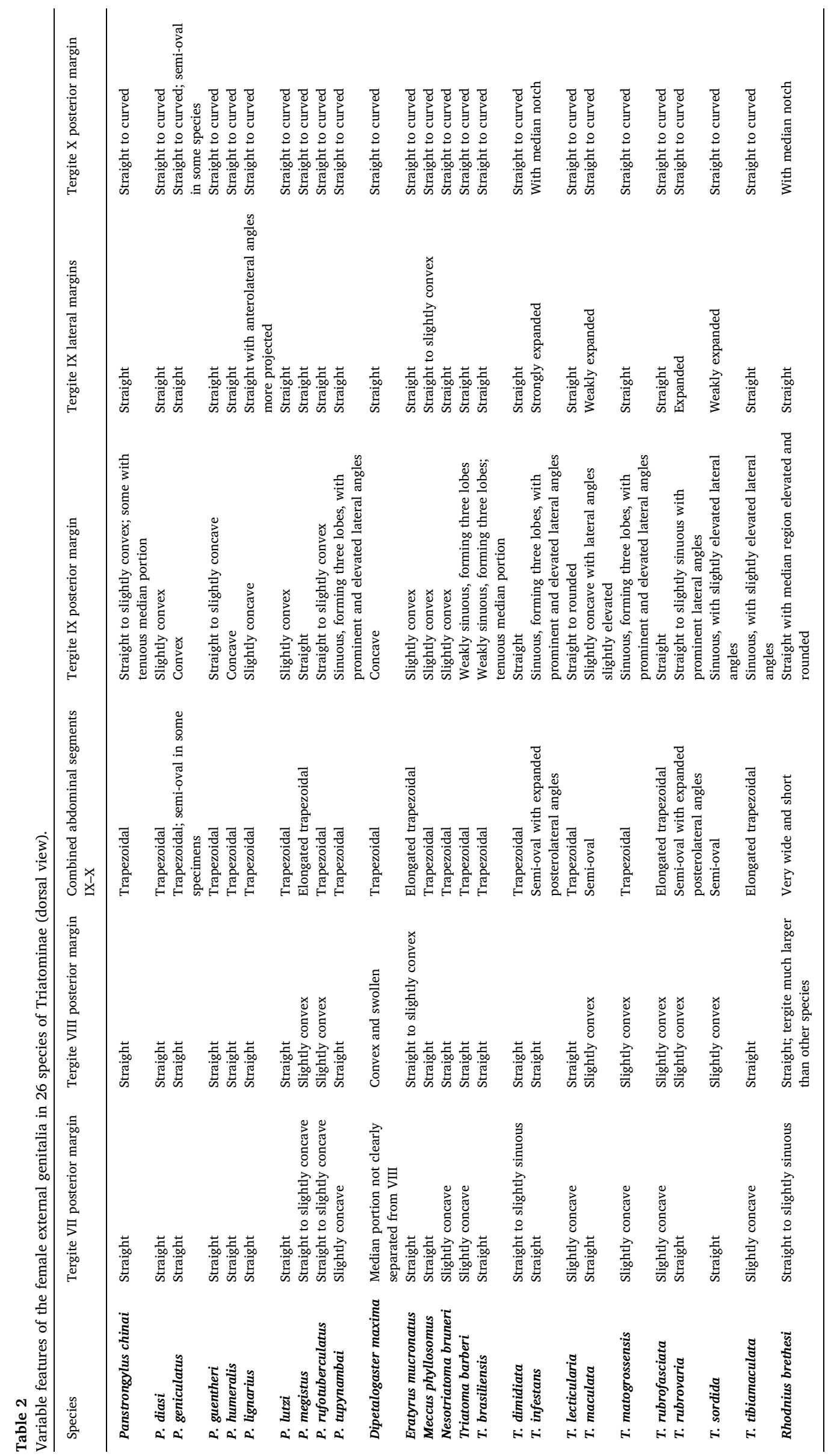




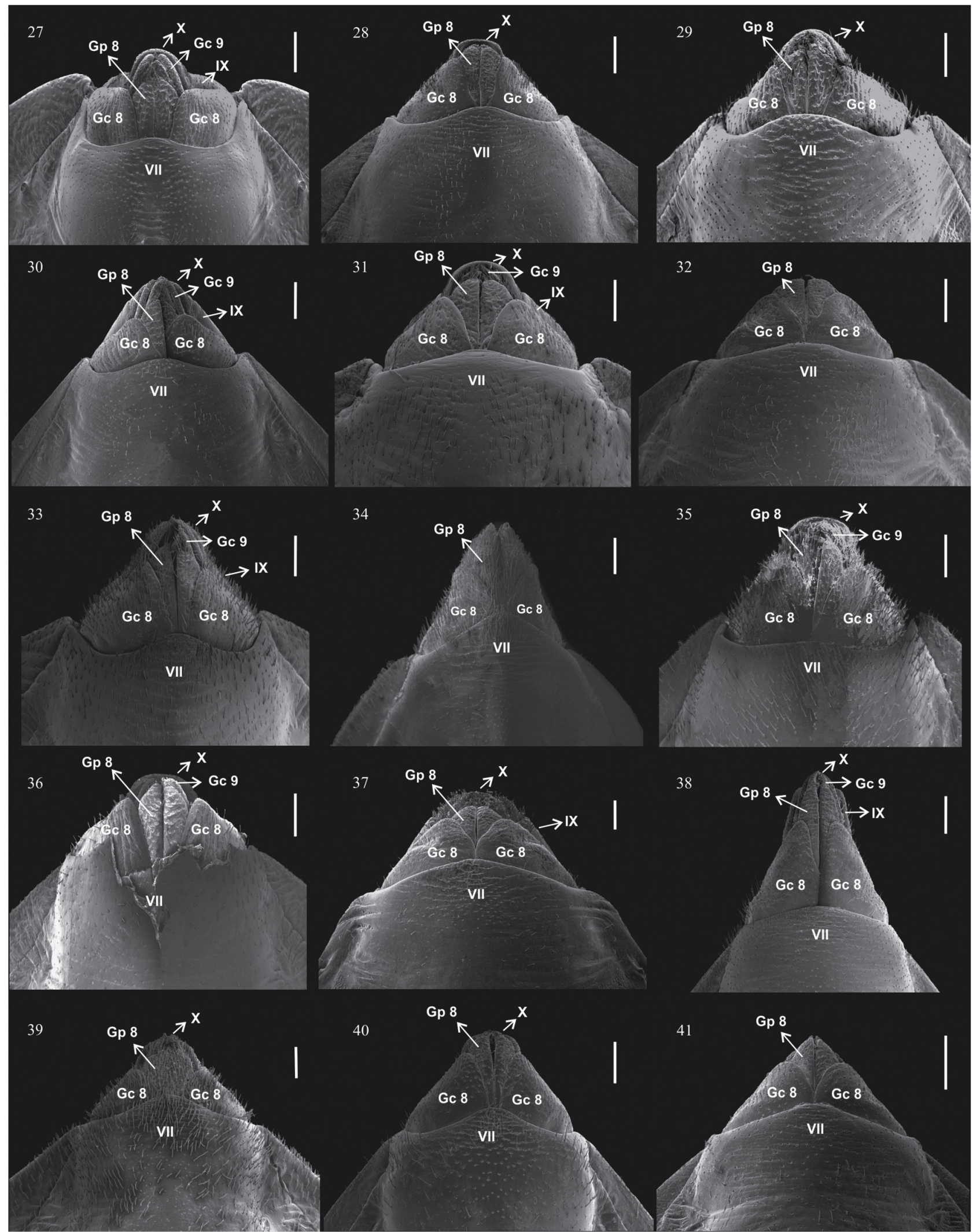

Figs. 27-41. Female external genitalia examined by scanning electron microscopy, ventral view: 27, Panstrongylus chinai. $28, P$. diasi. $29, P$. geniculatus. $30, P$. guentheri. 31, P. humeralis. 32, P. lignarius. 33, P. lutzi. 34, P. megistus. 35, P. rufotuberculatus. 36, P. tupynambai. 37, Dipetalogaster maxima. 38, Eratyrus mucronatus. 39, Meccus phyllosomus. 40, Nesotriatoma bruneri. 41, Triatoma barberi. (Gc8, gonocoxite VIII; Gc9, gonocoxite IX; Gp8, gonapophysis VIII; Gp9, gonapophysis IX; VII, sternite; IX and X, segments). Scale bars $=500 \mu \mathrm{m}$. 


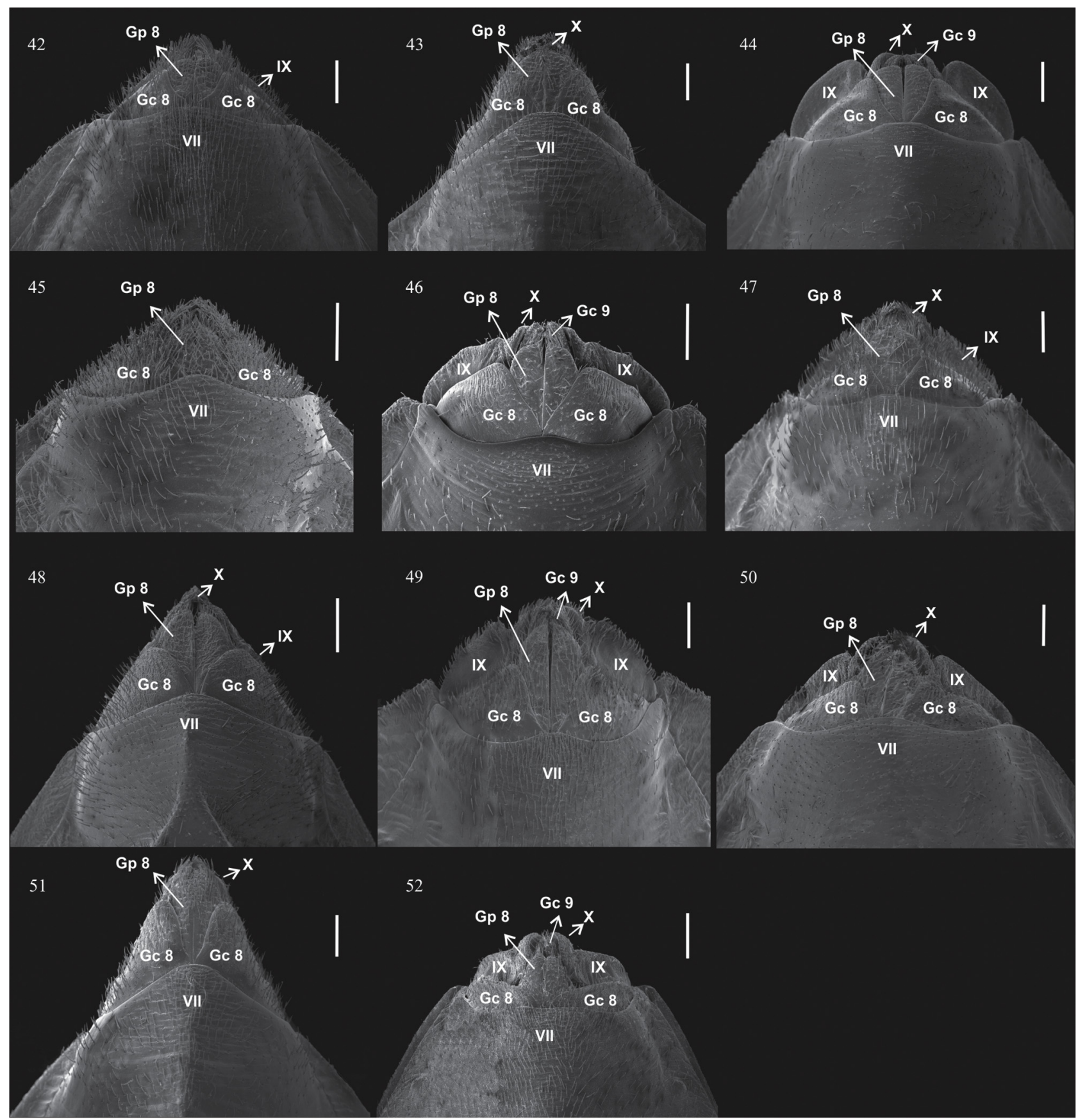

Figs. 42-52. Female external genitalia examined by scanning electron microscopy, ventral view: 42, Triatoma brasiliensis. 43, T. dimidiata. 44, T. infestans. 45, T. lecticularia. 46, T. maculata. 47, T. matogrossensis. 48, T. rubrofasciata. 49, T. rubrovaria. 50, T. sordida. 51, T. tibiamaculata. 52, Rhodnius brethesi. (Gc8, gonocoxite VIII; Gc9, gonocoxite IX; Gp8, gonapophysis VIII; Gp9, gonapophysis IX; VII, sternite; IX and X, segments). Scale bars $=500 \mu \mathrm{m}$.

35-37, 39-42, 44-47, 49-50, 52, 80, 83), except for P. megistus, E. mucronatus, T. dimidiata, T. rubrofasciata and T. tibiamaculata (longer than wide; Figs. 34, 38, 43, 48, 51).

Gonocoxites VIII usually triangular and convergent (Figs. $28-33$, 35-42, 44-50, 83), but sometimes not convergent, elongated ( $P$. megistus, E. mucronatus, T. dimidiata, T. tibiamaculata; Figs. 34, 38, 43, 51), or transversal with straight posterior margins (R. brethesi; Fig. 52). The last condition is an exception in P. chinai (Fig. 27), because most specimens have triangular, convergent plates (Fig. 80). Another character that is variable in $P$. chinai is the apex of the connexivum, which is wide and surpasses gonocoxite VIII in some specimens (Fig. 27), a condition not seen in other species of Panstrongylus. Gonapophysis VIII never elongated, but variable intraspecifically; usually longer in $E$. mucronatus, T. rubrovaria e T. tibiamaculata (Figs. 38, 49, 51).

Sternites IX and X, and gonocoxite IX visible or not depending on the position of the genitalia in the specimen. Sternite IX usually narrow, except for T. infestans, T. maculata, T. matogrossensis, T. rubrovaria, T. sordida and $R$. brethesi (Figs. 44, 46-47, 49-50, 52), in which it is expanded as can be seen in dorsal view (Figs. 18, 20-21, 23-24, 26).

\subsection{Posterior view (Figs. 53-78, 81, 84; Table 4)}

Lateral sclerites (appendices) between tergite VIII and gonocoxites VIII present in all species, but visible or not depending on the position and shape of tergite IX. Appendices never visible in species with tergite IX enlarged at base: P. humeralis, P. lignarius, T. brasiliensis, T. infestans, 
Table 3

Variable features of the female external genitalia in 26 species of Triatominae (ventral view).

\begin{tabular}{|c|c|c|c|c|}
\hline Species & $\begin{array}{l}\text { Sternite VII posterior } \\
\text { margin }\end{array}$ & $\begin{array}{l}\text { Combined abdominal segments } \\
\text { VIII-X }\end{array}$ & Gonocoxites VIII & Sternite IX \\
\hline Panstrongylus chinai & Sinuous & Wider than long & $\begin{array}{l}\text { Triangular and convergent or transversal with straight } \\
\text { apical margins }\end{array}$ & Narrow or not visible \\
\hline P. diasi & Sinuous & Wider than long & Triangular and convergent & Narrow or not visible \\
\hline P. geniculatus & Sinuous & Wider than long & Triangular and convergent & Narrow or not visible \\
\hline P. guentheri & Sinuous & Wider than long & Triangular and convergent & Narrow or not visible \\
\hline P. humeralis & $\begin{array}{l}\text { Straight, centrally } \\
\text { projected }\end{array}$ & Wider than long & Triangular and convergent & Narrow or not visible \\
\hline P. lignarius & Sinuous & Wider than long & Triangular and convergent & Narrow or not visible \\
\hline P. lutzi & Sinuous & Wider than long & Triangular and convergent & Narrow or not visible \\
\hline P. megistus & Sinuous & Longer than wide & Not convergent, elongated & Narrow or not visible \\
\hline P. rufotuberculatus & Sinuous & Wider than long & Triangular and convergent & Narrow or not visible \\
\hline P. tupynambai & Sinuous & Wider than long & Triangular and convergent & Narrow or not visible \\
\hline Dipetalogaster maxima & Sinuous & Wider than long & Triangular and convergent & Narrow or not visible \\
\hline Eratyrus mucronatus & Sinuous & Longer than wide & Not convergent, elongated & Narrow or not visible \\
\hline Meccus phyllosomus & Sinuous & Wider than long & Triangular and convergent & Narrow or not visible \\
\hline Nesotriatoma bruneri & Sinuous & Wider than long & Triangular and convergent & Narrow or not visible \\
\hline Triatoma barberi & $\begin{array}{l}\text { Straight, centrally } \\
\text { projected }\end{array}$ & Wider than long & Triangular and convergent & Narrow or not visible \\
\hline T. brasiliensis & Sinuous & Wider than long & Triangular and convergent & Narrow or not visible \\
\hline T. dimidiata & $\begin{array}{l}\text { Straight, centrally } \\
\text { projected }\end{array}$ & Longer than wide & Not convergent, elongated & Narrow or not visible \\
\hline T. infestans & Sinuous & Wider than long & Triangular and convergent & Strongly expanded \\
\hline T. lecticularia & Sinuous & Wider than long & Triangular and convergent & Narrow or not visible \\
\hline T. maculata & Sinuous & Wider than long & Triangular and convergent & Expanded \\
\hline T. matogrossensis & Sinuous & Wider than long & Triangular and convergent & Expanded \\
\hline T. rubrofasciata & $\begin{array}{l}\text { Straight, centrally } \\
\text { projected }\end{array}$ & Longer than wide & Triangular and convergent & Narrow or not visible \\
\hline T. rubrovaria & Sinuous & Wider than long & Triangular and convergent & Strongly expanded \\
\hline T. sordida & Sinuous & Wider than long & Triangular and convergent & Expanded \\
\hline T. tibiamaculata & Variably sinuous & Longer than wide & Not convergent, elongated & Narrow or not visible \\
\hline Rhodnius brethesi & Sinuous & Wider than long & Transversal with straight posterior margins & Expanded \\
\hline
\end{tabular}

T. maculata, T. matogrossensis, T. rubrovaria and T. sordida (Figs. 57-58, $68,70,72-73,75-76)$

Gonocoxites VIII elongated and narrow (Figs. 53, 55, 59-62, 81, 84); slightly wider (Figs. 54, 56, 63-78); or distinctly wider (Figs. 57, 58). Gonapophysis VIII and gonocoxites IX visible in all species.

Abdominal segments IX-X turned down, perpendicular to the body, longer than wide (Figs. 53, 55, 59-62, 81, 84); in the same plane of the body or slightly turned down, wider than long (Figs. 57-58, 63, 68, 70-76) or as wide as long (Figs. 54, 56, 64-67, 69, 77). R. brethesi has segments IX-X perpendicular to the body, but short and wide (Fig. 78).

Posterior margin of tergite IX medially tenuous or fused with tergite $\mathrm{X}$ in $P$. chinai, $P$. diasi (Pinto \& Lent, 1946), P. geniculatus, T. brasiliensis and T. maculata (Figs. 53-55, 68, 72, 81, 84); clearly separated from tergite $\mathrm{X}$ in other species (Table 4 ).

\section{Discussion}

Our results include new morphological data for several species of Triatominae and corroborate most findings of Rosa et al. (2010), with a few noteworthy exceptions: 1 ) the short combined segments IX and X in dorsal view cannot be considered diagnostic for Rhodnius, because this character is shared with non-congeneric species such as T. lecticularia and T. sordida; 2 ) the elongated trapezoidal dorsal shape of combined segments IX and X is found not only in species of Panstrongylus, but also in E. mucronatus and T. tibiamaculata; 3) our images show a clear separation between tergites VII and VIII of $P$. megistus, suggesting that either the specimen observed by Rosa et al. (2010) was dirty in this area or there is intraspecific variation (unseen in our material); 4) T. infestans displays variation in the posterior margin of tergite VII (with large median inflection as shown by those authors or straight as illustrated here) and in the tergite IX (with callosities near margins vs. without callosities); and 6) unlike stated by Rosa et al. (2010), the lateral margins of tergite IX are in fact slightly elevated in $P$. megistus, as well as in all species studied here.

We found diagnostic features at the generic level for Rhodnius and Dipetalogaster. The former has tergite VII very large, combined abdominal segments IX-X short, much wider than long, tergite IX short and wide, and posterior margin of tergite $\mathrm{X}$ with median notch; whereas the latter can be identified by the median portion of tergite VII not clearly separated from tergite VIII, the apex of the connexivum short, not reaching the posterior margin of tergite VIII, which is convex and swollen.

Small groups of species of Panstrongylus and Triatoma can be formed based on the same character, such as $P$. chinai, $P$. geniculatus, $P$. lutzi (Neiva \& Pinto, 1923), P. megistus, $P$. rufotuberculatus and $P$. tupynambai with segments IX and $\mathrm{X}$ in posterior view turned down, perpendicular to the body, longer than wide, with similar shapes; or Triatoma infestans, T. maculata, T. matogrossensis, T. rubrovaria and T. sordida with tergite IX expanded. However, non-congeneric species also share the same general aspect of the terminal abdomen, e.g. P. megistus, E. mucronatus, T. dimidiata, T. rubrofasciata and T. tibiamaculata with combined segments IX and $\mathrm{X}$ in dorsal view elongated, trapezoidal.

Tergite IX is the most valuable structure for distinguishing species. It can be: 1 ) longer than wide (P. megistus, E. mucronatus, $T$. dimidiata, $T$. rubrofasciata and T. tibiamaculata), very wide and short (R. brethesi), or wider than long (all other species); 2) posterior margin weakly to strongly sinuous, forming three lobes, with lateral angles more or less prominent and elevated (P. tupynambai, T. barberi, T. brasiliensis, T. infestans, T. matogrossensis, T. rubrovaria and T. tibiamaculata), straight with median region elevated and rounded ( $R$. brethesi), or straight to slightly convex or slightly concave (all other species); and 3) lateral margins weakly to strongly expanded (T. infestans, T. maculata, T. matogrossensis, $T$. rubrovaria and $T$. sordida) or straight to slightly convex (all other species).

Finally, the comparative study allowed us to identify, describe and encode 10 characters, five binary and five multistate, to be used in 

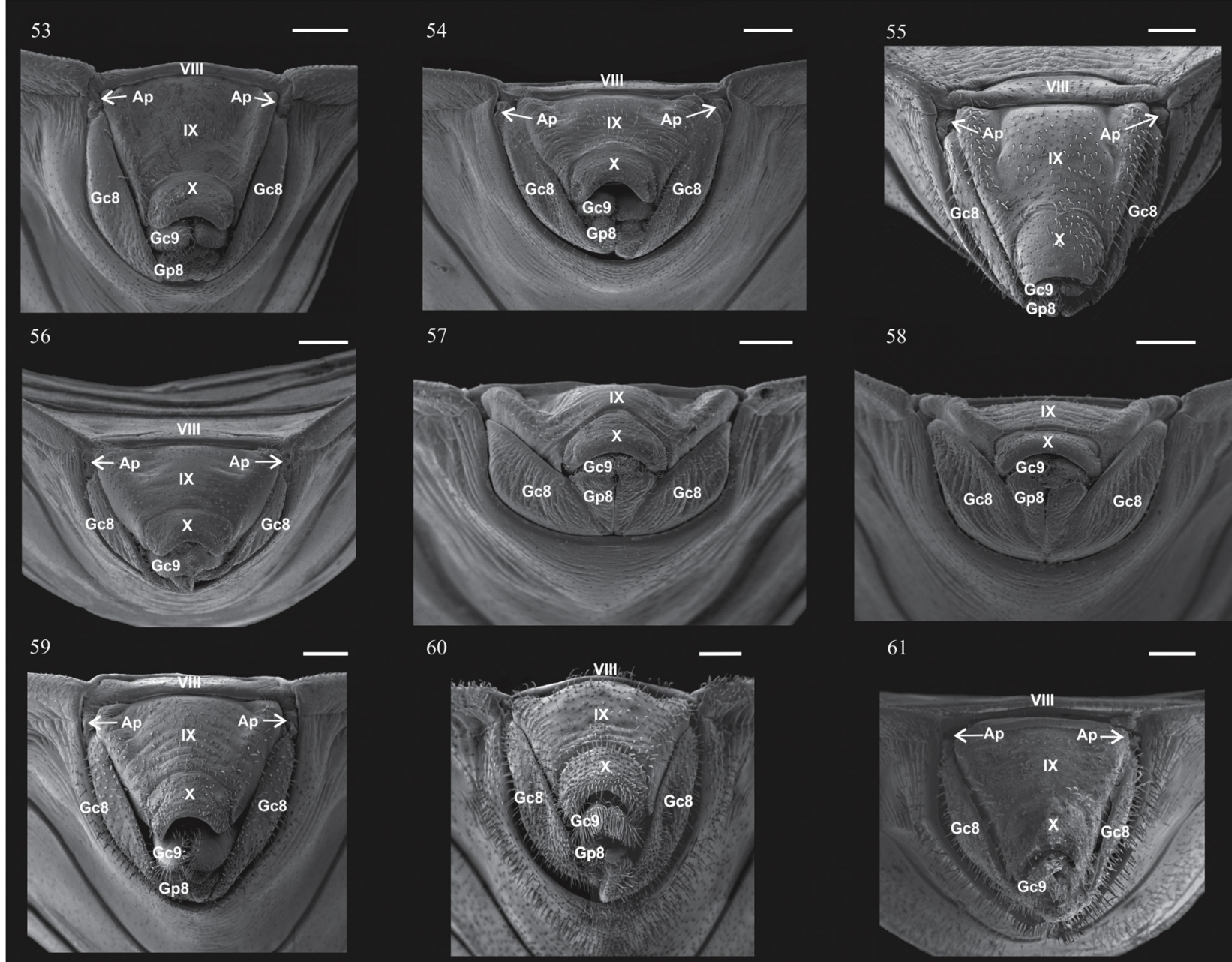

60
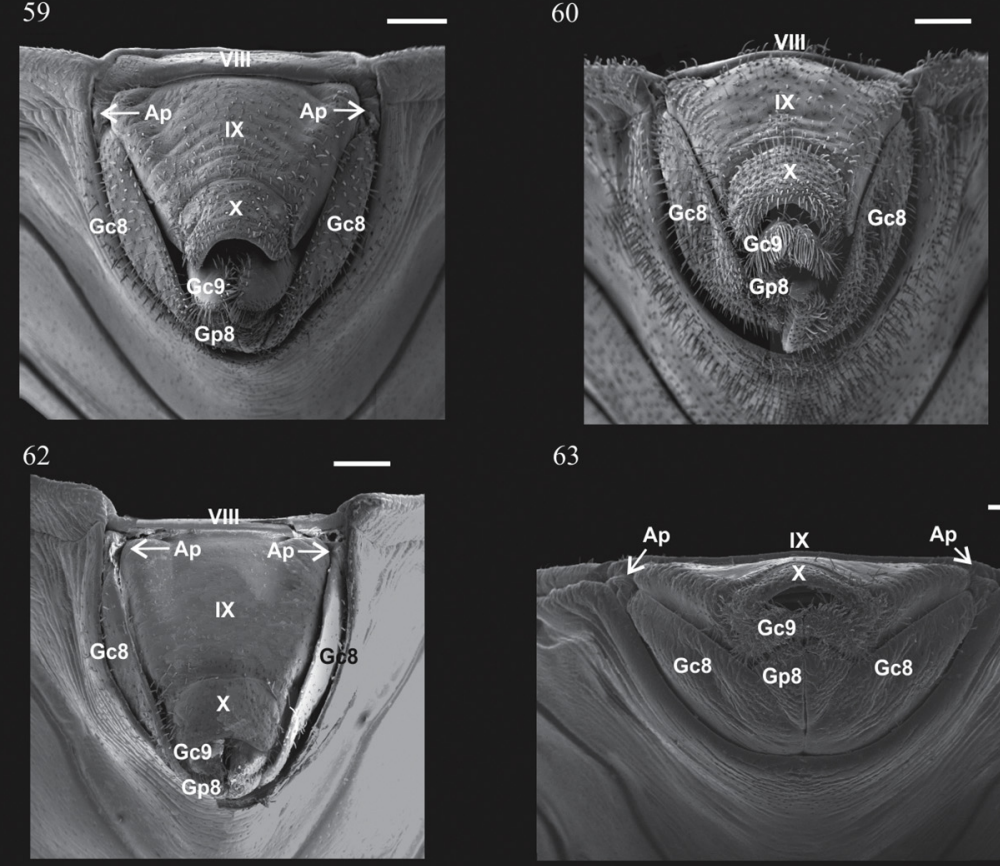

63

64
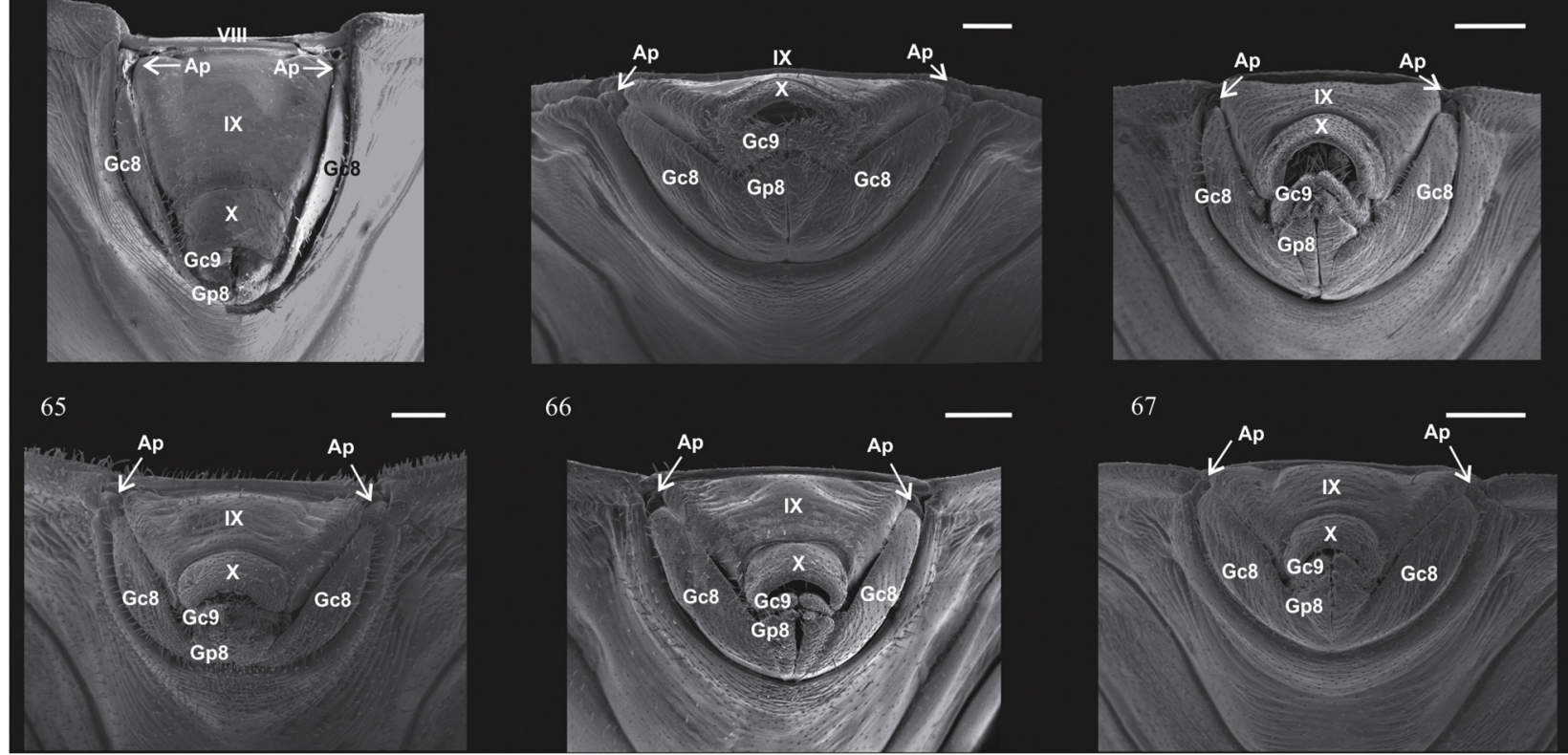

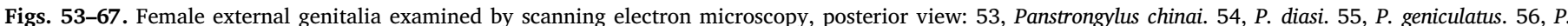

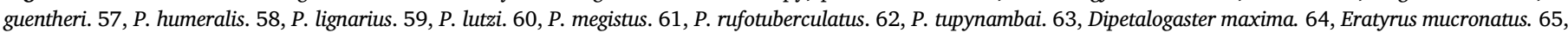

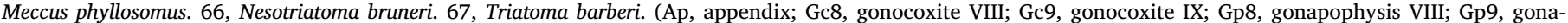
pophysis IX; VIII, tergite; IX and X, segments). Scale bars $=500 \mu \mathrm{m}$. 


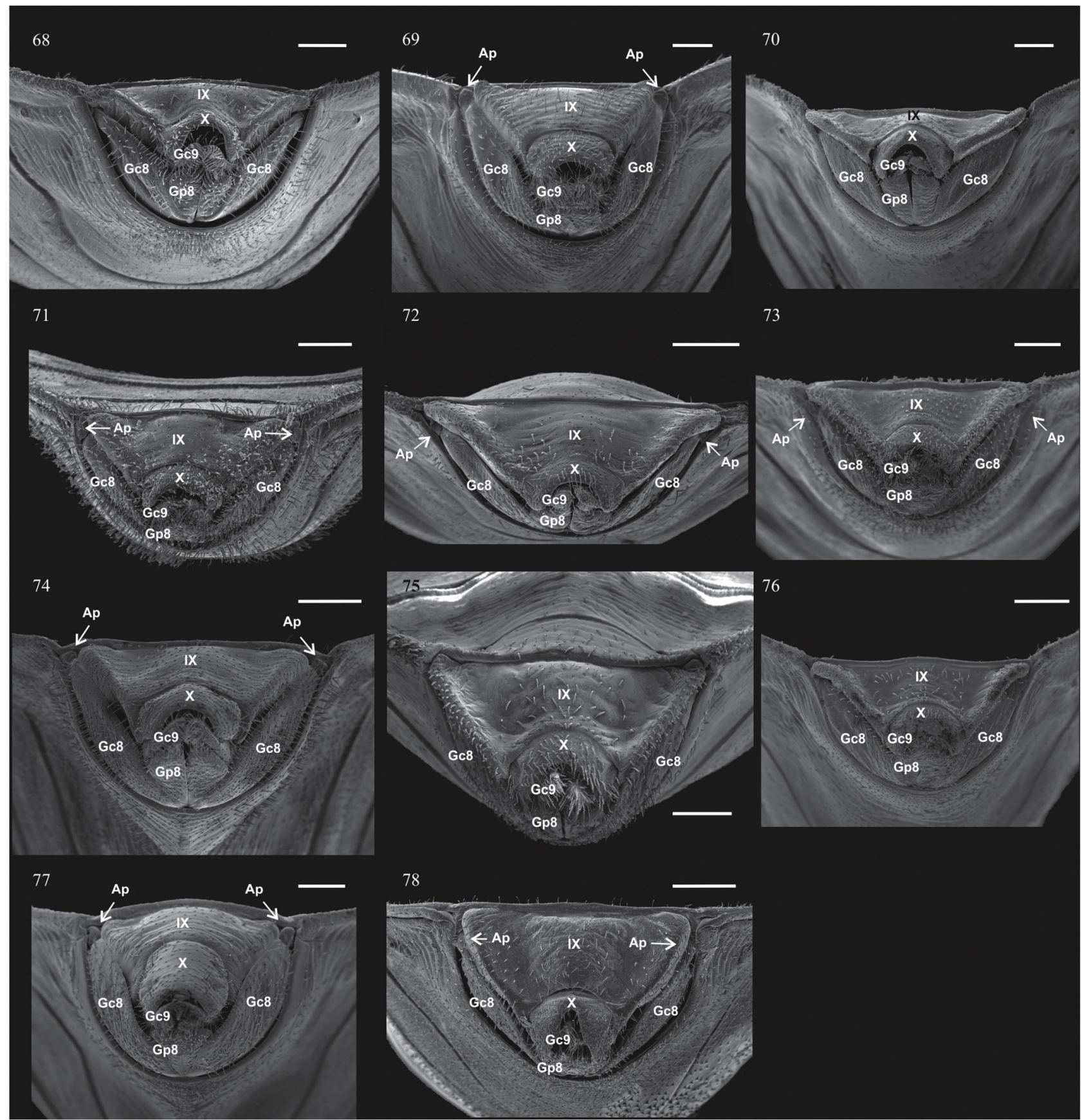

Figs. 68-78. Female external genitalia examined by scanning elecron microscopy, posterior view: 68, Triatoma brasiliensis. 69, T. dimidiata. 70, T. infestans. 71, T. lecticularia. 72, T. maculata. 73, T. matogrossensis. 74, T. rubrofasciata. 75, T. rubrovaria. 76, T. sordida. 77, T. tibiamaculata. 78, Rhodnius brethesi. (Ap, appendix; Gc8, gonocoxite VIII; Gc9, gonocoxite IX; Gp8, gonapophysis VIII; Gp9, gonapophysis IX; VIII, tergite; IX and X, segments). Scale bars $=500 \mu \mathrm{m}$.

cladistics analyses (available as supplementary data).

\section{Conclusion}

The female terminalia proved useful for the specific identification of Triatominae, but cannot be used to diagnose most genera or to directly assess supraspecific relationships. These can only be unveiled by using additional morphological and/or molecular data in broad cladistics analyses.

\section{Conflict of interest}

The authors declare no conflict of interests.

\section{Funding}

JMSR benefited from a PhD scholarship provided by the Oswaldo Cruz Institute and a sandwich scholarship provided by the Coordination for the Improvement of Higher Education Personnel (CAPES/PDSE/ Process \#88881.131622/2016-01). CG was supported by the National Council for Scientific and Technological Development (CNPq).

\section{Acknowledgments}

We thank Maria Emília Portela (LNIRTT) for providing specimens for our study; and Dr. Marcelo Ornaghi Orlandi, Dr. Mario Cilense, Sebastião Anésio Dametto (UNESP), Dr. Suzana Côrte Real Faria, Roger 

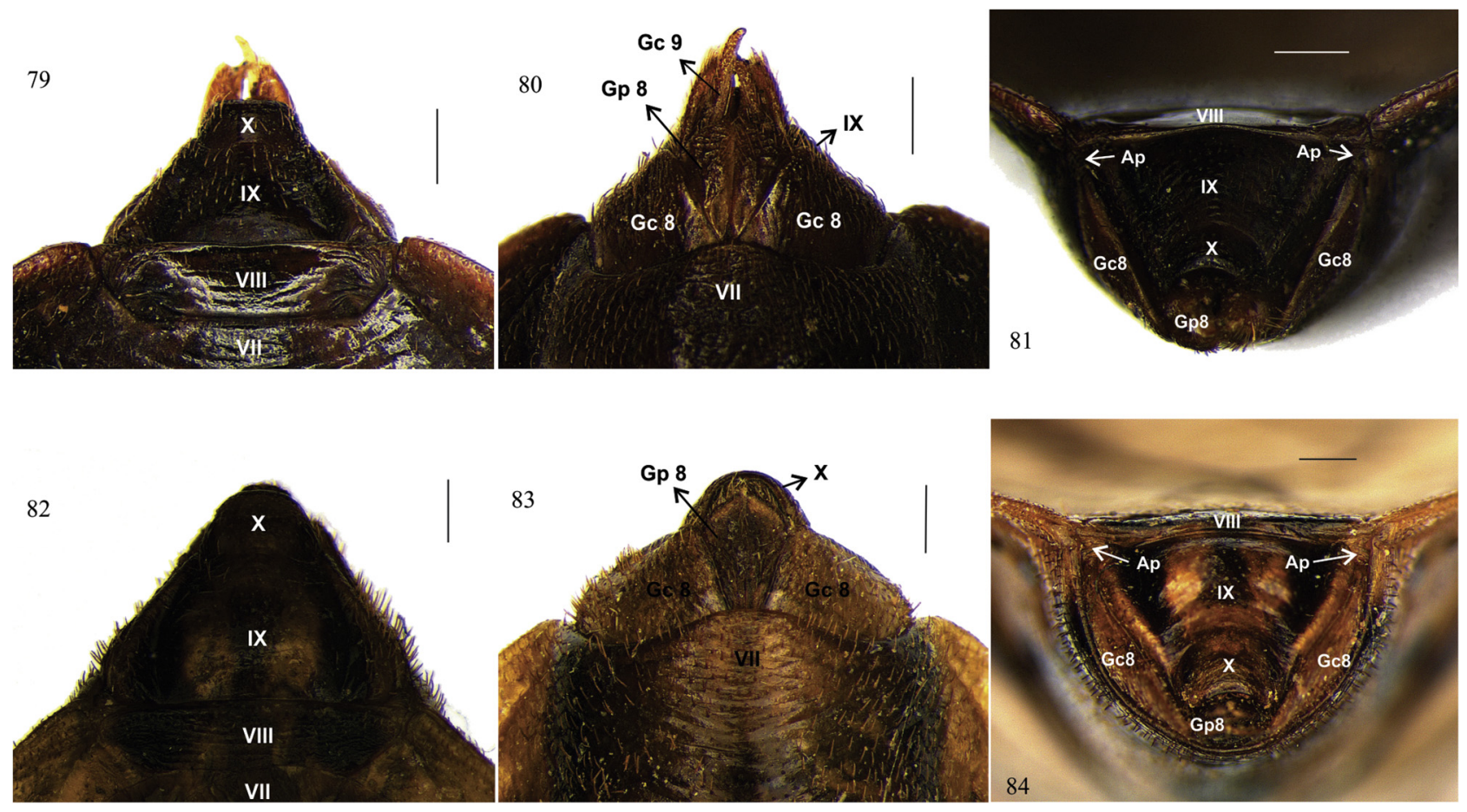

Figs. 79-84. High resolution digital photographs of the female external genitalia. 79-81, Panstrongylus chinai. 79, dorsal view. 80, ventral view. 81, posterior view. 82-84, P. geniculatus. 82, dorsal view. 83, ventral view. 84, posterior view. (Ap, appendix; Gc8, gonocoxite VIII; Gc9, gonocoxite IX; Gp8, gonapophyse VIII; Gp9, gonapophyse IX; VII and VIII, tergite; IX and X, segments). Scale bars $=0.5 \mathrm{~mm}$.

Table 4

Variable features of the female external genitalia in 26 species of Triatominae (posterior view).

\begin{tabular}{|c|c|c|c|c|}
\hline Species & Appendices & Gonocoxites VIII & Abdominal segments IX and $\mathrm{X}$ & Tergite IX posterior margin \\
\hline Panstrongylus chinai & Present and visible & Elongated and narrow & Turned down, perpendicular to the body, longer than wide & $\begin{array}{l}\text { Medially tenuous or fused with tergite } \\
\mathrm{X}\end{array}$ \\
\hline P. diasi & Present and visible & Elongated, slightly wider & $\begin{array}{l}\text { Slightly turned down, perpendicular to the body, longer than } \\
\text { wide }\end{array}$ & $\begin{array}{l}\text { Medially tenuous or fused with tergite } \\
\mathrm{X}\end{array}$ \\
\hline P. geniculatus & Present and visible & Elongated and narrow & Turned down, perpendicular to the body, longer than wide & $\begin{array}{l}\text { Medially tenuous or fused with tergite } \\
\mathrm{X}\end{array}$ \\
\hline P. guentheri & Present and visible & Elongated, slightly wider & $\begin{array}{l}\text { Slightly turned down, perpendicular to the body, longer than } \\
\text { wide }\end{array}$ & Clearly separated from tergite $\mathrm{X}$ \\
\hline P. humeralis & Not visible & Distinctly wider & In the same plane of the body, wider than long & Clearly separated from tergite $\mathrm{X}$ \\
\hline P. lignarius & Not visible & Distinctly wider & In the same plane of the body, wider than long & Clearly separated from tergite $\mathrm{X}$ \\
\hline P. lutzi & Present and visible & Elongated and narrow & Turned down, perpendicular to the body, longer than wide & Clearly separated from tergite $\mathrm{X}$ \\
\hline P. megistus & Present and visible & Elongated and narrow & Turned down, perpendicular to the body, longer than wide & Clearly separated from tergite $\mathrm{X}$ \\
\hline P. rufotuberculatus & Present and visible & Elongated and narrow & Turned down, perpendicular to the body, longer than wide & Clearly separated from tergite $\mathrm{X}$ \\
\hline P. tupynambai & Present and visible & Elongated and narrow & Turned down, perpendicular to the body, longer than wide & Clearly separated from tergite $\mathrm{X}$ \\
\hline Dipetalogaster maxima & Present and visible & Elongated, slightly wider & In the same plane of the body, wider than long & Clearly separated from tergite $\mathrm{X}$ \\
\hline Eratyrus mucronatus & Present and visible & Elongated, slightly wider & Slightly turned down, as wide as long & Clearly separated from tergite $\mathrm{X}$ \\
\hline Meccus phyllosomus & Present and visible & Elongated, slightly wider & Slightly turned down, as wide as long & Clearly separated from tergite $\mathrm{X}$ \\
\hline Nesotriatoma bruneri & Present and visible & Elongated, slightly wider & Slightly turned down, as wide as long & Clearly separated from tergite $\mathrm{X}$ \\
\hline Triatoma barberi & Present and visible & Elongated, slightly wider & Slightly turned down, as wide as long & Clearly separated from tergite $\mathrm{X}$ \\
\hline T. brasiliensis & Not visible & Elongated, slightly wider & Slightly turned down, as wide as long & $\begin{array}{l}\text { Medially tenuous or fused with tergite } \\
\mathrm{X}\end{array}$ \\
\hline T. dimidiata & Present and visible & Elongated, slightly wider & Slightly turned down, as wide as long & Clearly separated from tergite $\mathrm{X}$ \\
\hline T. infestans & Not visible & Elongated, slightly wider & Slightly turned down, wider than long & Clearly separated from tergite $\mathrm{X}$ \\
\hline T. lecticularia & Present and visible & Elongated, slightly wider & Slightly turned down, wider than long & Clearly separated from tergite $\mathrm{X}$ \\
\hline T. maculata & Not visible & Elongated, slightly wider & Slightly turned down, wider than long & $\begin{array}{l}\text { Medially tenuous or fused with tergite } \\
\mathrm{X}\end{array}$ \\
\hline T. matogrossensis & Not visible & Elongated, slightly wider & Slightly turned down, wider than long & Clearly separated from tergite $\mathrm{X}$ \\
\hline T. rubrofasciata & Present and visible & Elongated, slightly wider & Slightly turned down, wider than long & Clearly separated from tergite $\mathrm{X}$ \\
\hline T. rubrovaria & Not visible & Elongated, slightly wider & Slightly turned down, wider than long & Clearly separated from tergite $\mathrm{X}$ \\
\hline T. sordida & Not visible & Elongated, slightly wider & Slightly turned down, as wide as long & Clearly separated from tergite $\mathrm{X}$ \\
\hline T. tibiamaculata & Present and visible & Elongated, slightly wider & Slightly turned down, as wide as long & Clearly separated from tergite $\mathrm{X}$ \\
\hline Rhodnius brethesi & Present and visible & Elongated, slightly wider & In the same plane of the body, short and wide & Clearly separated from tergite $\mathrm{X}$ \\
\hline
\end{tabular}


Magno Macedo Silva, Wendell Girard Dias, Rômulo Custódio dos Santos, Taíssa Oliveira and José (IOC), for the valuable work on the scanning electron microscopy platforms of their institutions.

\section{Appendix A. Supplementary data}

Supplementary data associated with this article can be found, in the online version, at https://doi.org/10.1016/j.actatropica.2018.04.021.

\section{References}

Abalos, J.W., Wygodzinsky, P., 1951. Las Triatominae Argentinas (Reduviidae, Hemiptera). An. Inst. Med. Reg. Tucumán. Monogr. 2, 1-179.

De Paula, A.S., Diotaiuti, L., Schofield, C.J., 2005. Testing the sistergroup relationship of the Rhodniini and Triatomini (Insecta: Hemiptera: Reduviidae: Triatominae). Mol. Phylogenet. Evol. 35, 712-718. http://dx.doi.org/10.1016/j.ympev.2005.03.003.

Galvão, C., de Paula, A.S., 2014. Sistemática e evolução dos vetores. In: Galvão, Vetores, C. (Eds.), Vetores da Doença de Chagas no Brasil. Sociedade Brasileira de Zoologia, Curitiba, pp. 26-32. http://dx.doi.org/10.7476/9788598203096.

Lent, H., Jurberg, J., 1968. Estudo morfológico comparativo de "Panstrongylus geniculatus" (Latreille, 1811) e "Panstrongylus megistus" (Burmeister, 1835) e suas genitálias externas (Hemiptera, Reduviidae, Triatominae). Rev. Bras. Biol. 28 (4), 499-520.

Lent, H., Jurberg, J., 1969. O gênero Rhodnius Stal, 1859, com um estudo sôbre a genitália das espécies (Hemiptera, Reduviidae, Triatominae). Rev. Bras. Biol. 29 (4), 487-560.

Lent, H., Jurberg, J., 1975. O gênero Panstrongylus Berg, 1879, com um estudo sobre a genitalia externa das espécies (Hemiptera, Reduviidae, Triatominae). Rev. Bras. Biol. 35 (3), 379-418.

Lent, H., Wygodzinsky, P., 1979. Revision of the Triatominae (Hemiptera, Reduviidae) and their significance as vectors of Chagas' disease. Bull. Am. Mus. Nat. Hist. 163, $125-520$.

Lent, H., 1948. O gênero Rhodnius Stål, 1859 (Hemiptera: Reduviidae). Rev. Bras. Biol. 8, 297-339.

Mendonça, V.J., Alevi, K.C.C., Pinotti, H., Gurgel-Gonçalves, R., Pita, S., Guerra, A.L., Panzera, F., Araújo, R.F., Azeredo-Oliveira, M.T.V., Rosa, J.A., 2016. Revalidation of Triatoma bahiensis Sherlock \& Serafim, 1967 (Hemiptera: Reduviidae) and phylogeny of the T. brasiliensis species complex. Zootaxa 4107 (2), 239-254. http://dx.doi.org/ 10.11646/zootaxa.4107.2.6.

Patterson, J.S., 2007. Comparative Morphometric and Molecular Genetic Analyses of Triatominae (Hemiptera: Reduviidae). [Ph.D. Thesis]. 253 pp. University of London.

Rivas, N., Sánchez-Cordero, V., Camacho, A.D., Alejandre-Aguilar, R., 2017. External female genitalia of six species of the genus Meccus (Hemiptera: Reduviidae: Triatominae). J. Vect. Ecol. 42 (2), 271-278. http://dx.doi.org/10.1111/jvec.12267.

Rosa, J.A., Mendonça, V.J., Rocha, C.S., Gardim, S., Cilense, M., 2010. Characterization of the external female genitalia of six species of Triatominae (Hemiptera: Reduviidade) by scanning electron microscopy. Mem. Inst. Oswaldo Cruz 105 (3), 286-292. http:// dx.doi.org/10.1590/S0074-02762010000300007.

Rosa, J.A., Rocha, C.S., Gardim, S., Pinto, M.C., Mendonça, V.J., Ferreira Filho, J.C.R., Carvalho, E.O.C., Camargo, L.M.A., Oliveira, J., Nascimento, J.D., Cilense, M. Almeida, C.E., 2012. Description of Rhodnius montenegrensis n.sp. (Hemiptera: Reduviidae: Triatominae) from the state of Rondônia. Brazil. Zootaxa 3478, 62-76.

Rosa, J.A., Mendonça, V.J., Gardim, S., Carvalho, D.B., de Oliveira, J., Nascimento, J.D. Pinotti, H., Pinto, M.C., Cilense, M., Galvão, C., Barata, J.M., 2014. Study of the external female genitalia of 14 Rhodnius species (Hemiptera, Reduviidae, Triatominae) using scanning electron microscopy. Parasit Vectors 7, 17.

Rosa, J.A., Justino, H.H.G., Nascimento, J.D., Mendonça, V.J., Rocha, C.S., Carvalho, D.B., Falcone, R., Azeredo-Oliveira, M.T.V., Alevi, K.C.C., Oliveira, J., 2017. A new species of Rhodnius from Brazil (Hemiptera, Reduviidae, Triatominae). ZooKeys 675 1-25. http://dx.doi.org/10.3897/zookeys.675.12024.

Schofield, C.J., Galvão, C., 2009. Classification, evolution, and species groups within the Triatominae. Acta Trop. 110 (2-3), 88-100.

Schofield, C.J., 1994. Triatominae - Biología y Control. Eurocommunica Publications, West Sussex (80 pp).

Sherlock, I.A., Serafim, E.M., 1967. Triatoma lenti sp.n., Triatoma pessoai sp.n. e Triatoma bahiensis sp.n. do estado da Bahia, Brasil (Hemiptera: Reduviidae). Gaz Med Bahia 67, 75-92.

Souza, E.S., Von Artzingen, N.C.B., Furtado, M.B., Oliveira, J., Nascimento, J.D. Vendrami, D.P., Gardim, S., Rosa, J.A., 2016. Description of Rhodnius marabaensis sp.n. (Hemiptera, Reduviidae, Triatominae) from Pará State, Brazil. Zookeys 621, 45-62. http://dx.doi.org/10.3897/zookeys.621.9662.

WHO - World Health Organization, 2018a. Chagas Disease. (American trypanosomiasis) [homepage on the internet]. [Updated 2017 March; cited 2017 April 26]. Available from: http://www.who.int/mediacentre/factsheets/fs340/en/.ted.

WHO - World Health Organization, 2018b. What Is Chagas Disease? ([homepage on the internet]. [Updated 2017 March; cited 2017 April 26]. Available from: http://www. who.int/chagas/disease/en/). 